Article

\title{
Mobile Media and Social Space: How Anytime, Anyplace Connectivity Structures Everyday Life
}

\author{
Mariek Vanden Abeele ${ }^{1, *}$, Ralf De Wolf ${ }^{2}$ and Rich Ling ${ }^{3}$ \\ ${ }^{1}$ Department of Communication and Cognition, Tilburg University, 5000 Tilburg, The Netherlands; \\ E-Mail: m.m.p.vandenabeele@tilburguniversity.edu \\ 2 Department of Communication Sciences, imec-mict, Ghent University, 9000 Ghent, Belgium; E-Mail: ralf.dewolf@ugent.be \\ ${ }^{3}$ Wee Kim Wee School of Communication, Nanyang Technological University, 308232 Singapore, Singapore; \\ E-Mail: riseling@gmail.com \\ * Corresponding author
}

Submitted: 31 January 2018 | Accepted: 6 April 2018 | Published: 25 May 2018

\begin{abstract}
Using Giddens' (1984) structuration theory we examine how social structures in mobile communication technologies shape the everyday life of individuals, thereby re-shaping power dynamics that underlie the social organization of society. We argue that the anytime, anyplace connectivity afforded by mobile communication technologies structures society by imposing a network, social and personal logic. We discuss how each logic both reproduces and challenges traditional power structures, at the micro- as well as macro-level. At the micro-level, the network logic refers to mobile communication technologies' capacity to organize activities in a networked fashion, granting people greater autonomy from time and place. The social logic refers to mobile communication technologies' capacity for perpetual contact, fostering social connectedness with social relationships. The personal logic refers to mobile communication technologies' capacity to serve as extensions of the Self, with which people can personalize contents, services, place and time. The flipside of these logics is that, at the micro-level, the responsibility to operate autonomously, to maintain personal social networks, and to manage and act based on personal information shifts to the individual. We also notice shifts in power structures at the macro-level. For instance, to reap the benefits of mobile communication technology individuals engage in free 'digital labor' and tolerate new forms of surveillance and control.
\end{abstract}

\section{Keywords}

Giddens; logics; mobile media; power; responsibilization; social structure

\section{Issue}

This article is part of the issue "Rethinking Media and Social Space", edited by André Jansson and Johan Lindell (Karlstad University, Sweden).

(C) 2018 by the authors; licensee Cogitatio (Lisbon, Portugal). This article is licensed under a Creative Commons Attribution 4.0 International License (CC BY).

\section{Introduction}

Over the past decade, ubiquitous connectivity has become ingrained in everyday life. We use mobile communication technologies such as smartphones, tablets and laptops to interact with others, with services and with our device wherever we are and whenever we want. As Deuze (2011) argues, we reach a situation where we live "in" rather than "with" media, as these can no longer be seen as separate from us and become invisible because they are everywhere. This appears particularly true of mobile communication technologies, as we take their anytime, anyplace connectivity for granted (Ling, 2012). The taken-for-grantedness of mobile technologies is unfortunate, as it makes us overlook their role in shaping new power structures. Kubitschko and Knapp (2012, p. 362) mention in that regard that Deuze's media life ontology misses "any sense of materialization in relation to the mediatization of the social". Mobile communication technologies shape both offline and online social action. 
Thus, if anything, we need to recognize how the use of mobile communication technologies underpins contemporary life.

If we wish to understand how mobile communication technologies shape everyday life and the power dynamics that underlie it, we must focus on the social structures (cf. DeSanctis \& Poole, 1994) in these technologies. Social structures are the patterned ways in which everyday life is socially organized (Wellman \& Berkowitz, 1988). They enable and constrain human action by prescribing a way of 'doing things', and are reproduced every time people 'follow the prescription'. Because structures depend on human action, however, humans may also reflect upon, challenge, alter and resist them (Giddens, 1984). When the latter is done collectively, social change (i.e., re-structuring) may take place.

This interplay between structure and individual agency, also known as "duality of structure" (Giddens, 1984), can also be found in the relationship between technology and human agency (cf. Orlikowski's, 1992, duality of technology). Adaptive structuration theory (DeSanctis \& Poole, 1994) argues that there are social structures inherent in technologies. These social structures can be understood as templates, as "rules and resources provided by technologies...as the basis for human activity" (p. 125). Technologies structure human behavior because their affordances enable and constrain human action while, simultaneously, human agents structure the technology by designing, producing and marketing it, appropriating it (or not), and embedding it into everyday life (Hutchby, 2001).

The aim of this theoretical article is to unravel how the technological structuration process takes shape on the ground in the context of mobile communication technologies. To that end, we first argue that the concept of a 'logic' lends itself well to explain at least three dominant social structures in mobile communication technologies. Second, for each logic, we examine the micro-level implications of technological structuration processes in everyday life by zooming in on the ways in which processes and routines in everyday are altered. Finally, in a third section we discuss the flipside of these logics, both at the micro- and macro-level. At the micro-level, we examine subtle ways in which power is re-negotiated at the micro-level. At the macro-level, we examine how the technological structuration process interacts with general structuration processes, thereby reproducing and reshaping institutional power dynamics. Overall, our conceptual analysis serves as a lens that helps understand, structure, describe and discuss the implications of anyplace, anytime connectivity.

\section{Social Structures in Mobile Communication Technologies: Network, Social and Personal Logic}

Social structures are prescriptive: they specify a way of "doing things" (Giddens, 1984). Because of their prescriptive nature, structuration can be described as a process of installing a logic in society. A logic is a set of principles that makes it logical to organize things repeatedly and systematically in a certain manner. For example, when we consider gender as a social structure, we understand the gender structuration process as one of installing and maintaining a set of principles that make it logical to confer advantages and disadvantages systematically and repeatedly to people based on their gender. The logic of a system needs a rather continual set of events that underscore or illuminate the existence of the legitimized "way of doing things".

Similar to how a social category such as gender represents a social structure, we can find social structure in technologies. These structures reflexively shape society at the micro-level by changing processes and routines in everyday life, and at the macro-level by supporting social change and thus an altering of the institutional order. This symbolic interactionist view on the interplay between media technologies and society has been captured in the 'media logic' concept (cf. Altheide, 2013; Altheide \& Snow, 1985). This concept has been successfully applied to understand the social implications of, for example, social media (Van Dijck \& Poell, 2013) and digital news (Dahlgren, 1996).

In the current article, we apply the concept onto mobile communication technologies, by looking at the logics in mobile communication technology that direct human behavior-not deterministically, but rather by providing humans with both a "rationality of means" (Katz \& Aakhus, 2002, p. 306) and "constraint upon possibilities" (p. 307). We argue that by enabling people to be "Permanently Online, Permanently Connected" (POPC; cf. Vorderer, Krömer, \& Schneider, 2016) the dominant affordance of mobile communication technology is anytime, anyplace connectivity. This anytime anyplace connectivity alters both our daily routines and institutional forms. To understand the way in which daily routines and institutional forms are changing, we can analyze the logics underlying these processes of change. We differentiate three logics: a social-, a network- and a personal logic. Given the convergence of different services and platforms into one smartphone device, these three logics are undoubtedly not the only logics present in contemporary mobile communication technologies. We posit, however, that these three logics explain the dominant ways in which mobile communication technologies have shaped everyday life, thereby offering new opportunities, but also challenges at both the micro- and macro-level.

\section{Social Logic}

For Giddens (1990), the invention of the mechanical clock "emptied" time by introducing a universal system that separates space from time and standardizes time across regions. The latter ensures processes of 'disembedding', which he describes as processes that 'lift out' social activity from localized contexts, recognizing social relations across large time-space distances" (p. 53). Mo- 
bile communication technologies amplify this lifting out of social activities from their localized contexts. This is particularly noticeable in the social domain, where these technologies made it commonsensical for people to disembed their social life from time and space by organizing it in a 'connected' manner (Chayko, 2012; Licoppe \& Heurtin, 2001).

Katz and Aakhus (2002) mention a logic of "perpetual contact" as a driving force of people's use, judgment and interpretation of mobile communication technologies. This logic is a "socio-logic", based on a shared understanding of the interactional affordances of mobile phone technology that spreads through people's interactions with one another. The notion of a socio-logic resonates with Simmel's (1950) sociation and Bourdieu's (2005) habitus concept. As Katz and Aakhus (2002) argue, the logic of perpetual contact is rooted in a fundamental human desire for "pure communication" (Peters, 1999, as cited in Katz \& Aakhus, 2002), a communication unhindered by any form of constraint, be this time, space or even our bodies ("like the talk of angels") (Katz \& Aakhus, 2002, p. 307). Indeed, what characterizes humanity is our fundamental need to belong. According to Baumeister and Leary (1995), this need can be fulfilled when (1) a person has frequent and positively valenced interpersonal interactions, that (2) take place in the context of interpersonal relationships characterized by stability and affective concern. In short, people need a certain quantity of qualitative interactions with persons they have a durable interpersonal relationship with.

During modernity, however, industrialization and associated developments in urbanization and modern transportation have led to more dispersed social networks, or 'psychological' rather than geographical neighborhoods (Ling, 2017; Wurtzel \& Turner, 1976). Moreover, processes of de-traditionalization and individuation led to greater individual autonomy in the choice of one's personal relationships (Giddens, 1984, 1991, 1993). Giddens (1993) speaks in this regard of the 'pure' relationship: a relationship not prescribed by tradition but whose virtue is solely to fulfill partners' need to belong.

Over the past three decades, processes of industrialization and urbanization continued, at an even faster pace and in a more globalized fashion (Castells, 2009), leading Rosa (2013) to observe that the dominant feature of contemporary society is acceleration. In people's everyday lives, acceleration manifests itself in the experience of life as fast-paced, as if one is constantly balancing on a slippery slope. People indeed report feeling harried and under time pressure in everyday life (e.g., Mattingly \& Sayer, 2006). In such a society, maintaining frequent interactions in the context of stable and affectively caring 'pure' relationships becomes challenging-a challenge that lies on the shoulders of the individual. Mobile communication, and particularly text-based communication provides an answer to this challenge.

With respect to the frequency of communication, the interactional affordances of mobile messengers and mo- bile social media enable people to be in perpetual contact (Ling \& Lai, 2016). People have short, yet frequent, mobile interactions with their significant social relationships that seamlessly weave together into day- or even week-long conversations, contributing to a state of "connected presence" (Licoppe, 2004) in which others may be physically absent, but virtually present. The oftentimes phatic (cf. Malinowski, 1972) nature of these interactions plays into the maintenance of social relationships. Seemingly superficial interactions, such as the 'ephemeral' exchanges on Snapchat (a social media application where messages disappear after a predefined amount of time), carry a significant symbolic load, as they testify that people think about each other during their mundane activities, and take time and effort to inform each other of that. People also use mobiles for ritualized communication, including 'social-exchange' rituals in which complex norms regulate reciprocity and govern how trust is negotiated (Ling, 2008b; Taylor \& Harper, 2003). In short, the social logic in mobile communication technologies fosters social connectedness in a society in which relationship maintenance has become more challenging.

\section{The Network Logic}

The network logic refers to the fact that the social structures inherent in mobile communication technologies have made it logical for people to organize their activities in a 'networked' manner (Castells, Fernandez-Ardevol, Qiu, \& Sey, 2009; Rainie \& Wellman, 2012). Indeed, in contemporary Western societies, people are accustomed to directly access persons, services and information irrespective of time and place. For example, we check our work email during a restroom break, and progressively determine when and where to meet with friends.

The network logic inherent in digitally mediated mobile communication has restructured the social organization of society by no longer defining social relationships and activities in terms of the place where and the time when they take place. Giddens (1991) refers to this as "time-space distanciation". With respect to place, we see that social relationships and activities are increasingly defined by the "space of flows" (Castells et al., 2009), i.e., the communication and information that flows between the nodes who are in these places. For example, communication and information exchange between a teacher and their students can run from places such as the teacher's personal home, the office, or the train into students' homes, workplaces or favorite bar. The teacher-student relationship and the associated social activities are thus defined not by place (i.e., the auditorium or the office) but by the interaction and the communication channel. As a result, the space of flows disentangles a person's social role-the set of behaviors, beliefs, norms, obligations that come with a social positionfrom his/her location.

Mobile technologies have contributed not only to disentangling the relationship between social activity and 
place but also of the relationship between social activity and time. Social activities were traditionally organized in terms of sequentially ordered clock time, with one activity apportioned to each time slot. While clock time remains essential for the operation of major social institutions, we see that mobile communication enables people to organize activities in a much more flexible manner, for instance by allowing them to 'compress time' by carrying out multiple activities concurrently (Castells et al., 2009; Green, 2002). The de-sequencing of time that mobile devices enable, contributes to a continuous temporal and simultaneously spatial "boundary rearrangement" in everyday life (Green, 2002); people use mobile devices both to arrange when and where activities start and end, and to start and end them in the moment itself. The continuous rearrangement of social activities afforded by mobile interaction makes events more simultaneous, instantaneous and perhaps disjointed. A consequence is that people are only certain about what occurs in the present and the immediate future, i.e., in the "present extensive" (Marcía-Montes, Caballero-Muñoz, \& PérezÁlvarez, 2006). For example, when a CEO receives an urgent mobile call from work (e.g. a worker not showing up for his/her shift) during a family pick nick, she may need to rearrange the work situation on the spot, for example by instantly rearranging the social activities of other employees to cover for the tardy worker.

By removing space and time constraints, the network logic inherent in mobile communication technologies affords people greater autonomy over their personal life as it provides them with the opportunity to tap "into the[ir] sparsely knit networks of diverse associates rather than rely on tight connections to a relatively small number of core associates" (Rainie \& Wellman, 2012, p. 12). People rely less on time and space as an intermediary to organize daily activities (Ling, 2004). The primary example of this autonomy is how we use mobile communication technologies to "micro-coordinate" the logistics of everyday life (Ling \& Haddon, 2003; Ling \& Yttri, 1999). Activities can be adjusted mid-course, and their coordination can be progressively refined, so as to best accommodate each individual's personal schedule. Mobile access to other people, but also mobile access to information and services (e.g., on delays in public transportation) enables people to flexibly align themselves to ad hoc situations (Bertel, 2013).

\section{The Personal Logic}

The personal logic refers to the observation that the social structures inherent in contemporary mobile communication technologies embody processes of personalization (Campbell \& Park, 2008). By enabling anytime, anyplace connectivity, mobile communication technologies enable people to personalize time and space: Public space is personalized, as people can disengage from any physical setting by drawing up symbolic fences us- ing their mobile communication technology, even if that means breaking social arrangements (e.g., when voice calling during a theatre performance; Ling, 2008a). Time is also personalized when, for example, people use mobile communication technologies to instantly renegotiate their schedules depending on personal preferences and circumstances (Ling \& Haddon, 2003). Because of time-space distanciation (Giddens, 1991), mobile communication technologies also enable people to develop, manage and access highly personal networks (Campbell \& Park, 2008). This aspect of personalization is perhaps most visible in the lives of young teenagers, for whom the device enables 'personal' communication with friends, 'under-the-radar' of parents or other authority figures (Ling \& Yttri, 1999; Vanden Abeele, 2016).

With the advent of mobile, internet, and smartphone technology, personalization as a logic has become even more pervasive. In contemporary societies, people have access to contents and services on their mobile communication technologies tailored to their preferences based on personalization recommendation systems (e.g., Netflix, Spotify, news items to which they are exposed, etc.), and they increasingly consume these contents and services on demand. The trend towards personalized, ondemand consumption has disrupted entire industries, but also significantly re-structured everyday practices, offering new opportunities (e.g., decreasing advertising clutter) as well as challenges (e.g., binge viewing).

Finally, a mobile device itself is a personal and also potentially personalized object (decorated with covers) (e.g., Katz \& Sugiyama, 2016). The materiality of the device itself is symbolic: like with other possessions (cf. Belk, 1988), we can come to consider it an extension of the self (Vishwanath \& Chen, 2008) reflecting our personal and social identities. Wearable technologies embody the personal logic even further, by allowing persons to track a variety of personal parameters (e.g., health indicators) and to reflect on their meaning. This information may subsequently lead to better decisionmaking (Morris \& Aguilera, 2012). Finally, the 'personalness' also lies in the digital traces that we leave behind when using our mobile devices. These document our personal lives (cf. Hand, 2016), and enable others to reminisce us even after our death (Cumiskey \& Hjorth, 2017).

\section{The Flipside of the Social Structures of Mobile Communication Technologies}

In the previous sections, we used the lens of 'technological logics' to explain how the social structures inherent in mobile communication devices re-structure everyday life. We deduct from that analysis that the social-, network- and personal logic provide ample benefits to the processes and routines that make out people's everyday lives. However, there is a flipside to the social structures in mobile media, both at the micro- and the macro-level. 


\section{Consequences of Anytime, Anyplace Connectivity for the Individual: Responsibilization}

In describing the dominant dynamics of modernity, Giddens (1990) refers to reflexivity as a defining characteristic of human action. People have to 'keep in touch' with the grounds of what they are doing. The construction of the self becomes a reflexive project, as individuals find their identity "amid the strategies and options provided by abstract systems" (p. 124). Giddens defined this new life style as "life politics" (1991, p. 209). The life politics life style is characterized by self-actualization with an emphasis on individual responsibility.

At first glance, anytime, anyplace connectivity seems to support the life politics life style by creating new opportunities for individuals to organize their everyday social, work and personal activities more autonomously, aligned with their personal preferences and circumstances. In that regard, mobile communication technologies support ongoing processes of individuation and rationalization that characterize our late-modern society.

As mentioned above, a heightened reflexivity of individuals is central to processes of individuation and rationalization (Beck, Giddens, \& Lash, 1994). Such reflexivity is also central to the process of domesticating mobile communication technologies into one's daily life, as domestication (cf. Silverstone \& Haddon, 1996) requires a continuous negotiation of boundaries. Indeed, managing activities in a networked fashion (networked logic), building and maintaining 'pure' relationships (social logic), and constantly making decisions with respect to the tailoring of everyday identifiers (personal logic) can be seen as an ongoing negotiation of audiences, contents and boundaries in a collapsed and networked environment. The social, network and personal logic imply that individuals increasingly take responsibility in an environment where the social forms of time and space have become fluid and open, and boundaries permeable. Papacharissi and Gibson (2011, p. 78) mention in that regard that "modern and urban life charged individuals with the responsibility of managing their sociality, and their privacy, in unknown urban territory".

The social structures in mobile communication technologies thus force new processes of 'responsibilization' onto individuals that make them responsible for tasks for which they were previously not responsible (cf. Wakefield \& Fleming, 2009, p. 276). With respect to the network logic, for example, individuals have greater autonomy over when and where they wish to activate certain social roles, as the spatio-temporal context is a less decisive factor for deciding when social roles and their associated activities, norms, and values start and end. The flipside of this is that the responsibility for activating these social roles falls onto the individual's shoulders.

Disentangling social activities from place does not render physical places (Castells et al., 2009) nor contexts (Nissenbaum, 2009) irrelevant. Place and context are always there, but they become background rather than foreground for social activities. For example, the role of a professor is to educate students, engage in fundamental research and hold a mirror up to society. A professor acts in the context of a university where her/his duties are defined by norms that dictate what is acceptable and what is not. But even within this context, it is less clear today than it was before when the role of professor ends and that of, let's say, family member begins. What is clear is that it is up to the individual to make these decisions and define roles and relationships that used to be implicit or structured in their practices. The ongoing negotiation in academia, but also industries and education to help disconnect the networked self, shows resistance in the form of efforts to mitigate the latter processes of responsibilization. For example, in Germany, after-hours emails to employees of BMW and Volkswagen are put on hold or deleted (Hesselberth, 2017).

The social logic pushes responsibility onto the individual in the social realm. Mobile social media enhance a specific kind of sociability: a networked sociability that constitutes a networked self, where one is able to communicate in a converged environment across multiple audiences, which supposes a "sense of place reflexivity" (Papacharissi, 2011). Mobile social media also support relationship maintenance by enabling individuals to frequently interact with others in ways that re-establish trust in these relationships. However, "connected presence" (Licoppe, 2004) blurs the boundaries between the physical and virtual realm because the individual must evaluate when and where to prioritize the near-constant stream of virtual interactions over ongoing offline activities, thereby entering a state of "absent presence" (Gergen, 2002). Particularly when these offline activities are themselves of a social nature (e.g., family dinner or date), the situation becomes messy, as the co-present interaction must compete with online activities that may (or may not) include mediated social communication (Turkle, 2011). The notification systems of mobile social media applications put pressure on the individual to respond (cf. Hopper's, 1992, "caller hegemony"); but when individuals do so, they risk harming the offline social interaction they are engaged in (e.g., Vanden Abeele, Antheunis, \& Schouten, 2016).

The personal logic inherent in mobile communication technologies challenges individuals to make 'optimal' judgments at any time and place. Wearables, for example, offer new opportunities to monitor health (the 'quantified self'), but also make the individual responsible to act upon the monitored information. Individuals must decide if they desire this increased self-knowledge, taking into account that it may bestow guilt when, for example, the daily step count has not been reached. In addition, the individual user must be reflexive of these technologies, and realize, for example, that fitness-wearables typically normalize body weight and figure rather than taking into account the variety of possibilities. As Crawford, Lingel and Karppi (2015, p. 494) note, "users of wearables are told very little about the cultural and sci- 
entific assumptions that undergird notions of the normal user, and they are simply placed in percentiles that lack any transparency in their construction of use". In other words, they need to be reflexive of the fact that the promise of agency (here: self-knowledge) is embedded in a structure with its own logics (here: disciplining the human body).

In sum, we would like to argue that the logics in mobile communication technologies increasingly shift responsibility to the individual. Not only are individuals increasingly responsible for making decisions and delineating boundaries in mobile communication technologies; the very process of decision-making has become more individualistic as well.

\section{Consequences of Anytime, Anyplace Connectivity for Society: New Distributions of Power}

The logics in mobile communication technologies have brought about profound social change in society, not only in everyday life, but also in the broader economic, political, and cultural sphere (e.g., Castells, 2009). In this section, we focus on three processes in which mobile communication technologies reproduce, challenge and shift power: political change, commodification, and surveillance.

With respect to political change, we see that the ability to address individuals directly and instantaneously has enabled new forms of political organization and communication. Mobile communication technologies have become key technologies in processes of political change. For instance, during the 'Arab Spring' - the 'protest cascade' in the Middle East in 2011-they were used to capture and share images of key events (e.g., Mohamed Bouazizi who set himself on fire in protest), to microcoordinate protests in the streets 'below the radar' of the authorities, and to communicate with foreign media (Hussain \& Howard, 2013). More recently, private acts have shown to have a political effect. For example, the private sharing of pussyhat selfies and/or \#MeToo testimonials on (semi-)public social media platforms led to the social construction of feminist protest. According to Lindgren (2017, p. 156) "this hybrid dynamic is unique to the digital society, as these private acts can be carried out in personal, familiar, and autonomous spaces but still have the same potential audience as a public act". Mobile media thus enable low-threshold political participation, opening opportunities for a more participatory democracy. A flipside of not having to rely on an 'authority' such as the government or a news organization to obtain and exchange information is that information of unknown veracity may circulate. People are responsible for checking this veracity but may feel powerless to act upon that responsibility, as there is often a lack of transparency about the goals of the organizations producing and distributing the information. This sense of powerlessness may reflect itself in feelings of cynicism and alienation (e.g., Balmas, 2014). The observation that reflexive individu- als may feel powerless puts under stress Giddens' ideal of the information revolution as a path towards greater human agency: rather than a power shift from authorities to the individual, we may be witnessing a shift from authorities to organizations and corporations that control information.

The social logic is present in a wide range of mobile social media applications. These applications, however, blur the roles of a consumer and that of a laborer. Already in 1977, Smythe criticized media companies for supporting the commodification process when he conceptualized the audience as both a commodity and a worker (Smythe, 1977). He indicated that selling audiences to advertisers accumulated capital, shifting the audience that watches into an audience that works. If we draw a parallel with contemporary society, we can see that achieving a state of "connected presence" (Licoppe, 2004) requires an ongoing connection to third parties, or 'invisible virtual employers', often without our explicit consent or even awareness. On this topic, Van Dijck (2013, p. 4) argues that "connectivity quickly evolved into a valuable resource as engineers found ways to code information into algorithms that helped brand a particular form of online sociality and make it profitable in online markets". Indeed, events such as the recent commotion surrounding Facebook and Cambridge Analytica reveal that the logic of perpetual contact is supported by an 'automated connectivity' where media platforms are trying to steer everyday practices (Van Dijck, 2013). Media platforms encompass systems that generate a false consciousness, preventing us from perceiving the limited autonomy we are actually given. For example, platforms typically offer users more options to manage their interpersonal information flows than that they receive options to regulate the flows of information towards third parties and service providers (Heyman, De Wolf, \& Pierson, 2014).

The commodification of mobile media users and their mobile activities by third parties cannot be separated from the issue of technological surveillance. There are various ways in which mobile communication technologies underwrite a panopticon view on surveillance that further disempowers users. Foucault (1995) argued that the panopticon disposes an individual's subjectivity, reducing him/her to an object in a one-sided power relationship with those watching. According to him (p. 201), through a constant (feeling of) surveillance we internalize societal norms and values. The panopticon automatizes and de-individualizes power, making it also invisible and hard for people to criticize. This is applicable to the various, often 'free', mobile social media applications that we use. We produce highly personalized digital traces through these applications that are subject to 'dataveillance': a continuous tracking of our personal information by media corporations for unstated preset purposes (Van Dijck, 2014, p. 205).

The logics in mobile communication technologies do not only amplify panoptic surveillance; they also en- 
able other forms of surveillance. In our social networks, the social logic of perpetual contact blurs the role of watchers and of those watched. Marwick (2012) introduced the term "social surveillance" next to the typical panopticon surveillance concept. In situations of social surveillance, power is intrinsic to every relationship, and surveillance is reciprocal, meaning that actors can surveil one another-the many watch the many, denoted as 'omniopticon'. Besides social surveillance, Leaver (2017) warns for intimate surveillance where parental monitoring through wearable technologies, for example, is normalized and perceived as a necessity in a culture of care (where a good parent is one that watches and monitors).

However, mobile media also enable 'sousveillance' or grassroots surveillance, an inverse form of surveillance that challenges power by countering organizational surveillance (Mann, Nolan, \& Wellman, 2002). For example, citizens can use their mobile phone cameras to document police interventions. By using mobile media in ways that 'control' the controllers, individuals can challenge existing power structures and power relations.

\section{Conclusion: Mobile Media and Social Space}

This article presents three logics inherent in mobile communication technologies, a social, a network and a personal logic, and discusses how these alter social space at the micro-level, by structuring people's everyday practices, and re-shape social space at the macro-level, by affecting processes of social change (see Figure 1 for a graphical presentation).
Our analysis is not complete nor holistic, as the scope and depth of such an endeavor extends beyond what is possible in one article. However, we hope that the analytical lens presented can give impetus to further examinations of the relationship between mobile media affordances and social space, and of how social change is negotiated through that process. One particular point of consideration for such further examinations is that the social, network and personal logic are not the only logics inherent in mobile communication technologies. Because of technological convergence, current smartphone devices offer access to a multitude of services and media platforms. As a result, these devices have become a carrier of other logics, such as the social media logic (Van Dijck \& Poell, 2013) and the news media logic (Dahlgren, 1996), but they add anytime, anyplace access to them. A pertinent question is how the social, network and personal logic intersect with each other and with these other logics, potentially amplifying each other's working in certain areas of life, thereby accelerating social change, but potentially also disrupting each other, thereby hampering social change.

Examinations of the interplay between mobile media and social space are essential in order to understand how technological structuration processes intersect with general structuration processes in society. As for mobile media technologies, our analysis of the social, network and personal logic exemplifies that societal processes may be reinforced (e.g., individual responsibilization), challenged (e.g., political participation) and sometimes even reversed (e.g., sousveillance) when the structures inher-
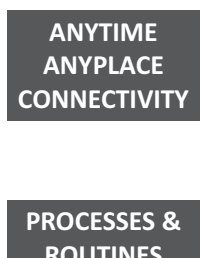

ROUTINES

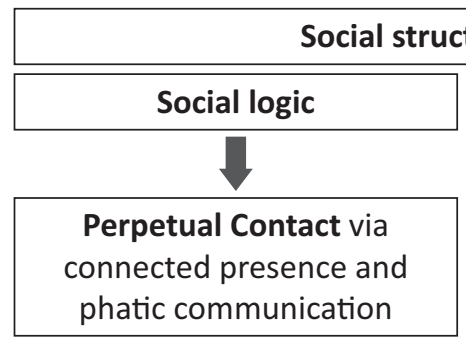
phatic communication
Autonomy by disentangling social relations and activities from time and place

\begin{tabular}{|c|}
\hline Network logic \\
\hline $\begin{array}{c}\text { Autonomy by disentangling } \\
\text { social relations and activities } \\
\text { from time and place }\end{array}$ \\
\hline
\end{tabular}

\begin{tabular}{|c|}
\hline Personal logic \\
\hline Personalization via on- \\
demand access to tailored \\
activities, services, objects \\
\hline
\end{tabular}

\section{INDIVIDUAL}

CONSEQUENCES

(MICRO-LEVEL)

\begin{tabular}{|c|}
\hline Responsibility pushed onto \\
individual to decide when \\
virtual sociality intersects \\
with physical reality
\end{tabular}

Responsibilization (examples)

Responsbility pushed onto individual to decide when and where to activate and end social roles
Responsibility pushed onto individual by individualizing decision-making processes in various life spheres
INSTITUTIONAL CONSEQUENCES (MACRO-LEVEL)

\begin{tabular}{|c|c|c|c|c|}
\hline \multicolumn{4}{|c|}{ New distributions of power (examples) } \\
\hline $\begin{array}{c}\text { Commodification of } \\
\text { social media users } \\
\text { who 'work' for }\end{array}$ & $\begin{array}{c}\text { Shifts in who controls } \\
\text { and disseminates } \\
\text { information enable new } \\
\text { (invisible ) } 3^{\text {rd }} \text { parties }\end{array}$ & $\begin{array}{c}\text { Hybrid dynamic } \\
\text { enables public } \\
\text { porms of participation }\end{array}$ & $\begin{array}{c}\text { Increased surveillance } \\
\text { through dataveillance- } \\
\text { private acts }\end{array}$ & $\begin{array}{c}\text { reversed surveillance } \\
\text { through sousveillance }\end{array}$ \\
\cline { 2 - 5 }
\end{tabular}

Figure 1. A visual presentation illustrating how the social, network and personal logic in mobile communication technologies affect processes and routines in everyday life, and, in turn, contribute to social change at the micro- and macro-level. 
ent in mobile technologies are brought into action by individual users.

\section{Acknowledgments}

The authors thank the anonymous reviewers for their constructive feedback and suggestions regarding this article.

\section{Conflict of Interests}

The authors declare no conflict of interests.

\section{References}

Altheide, D. L. (2013). Media logic, social control, and fear. Communication Theory, 23(3), 223-238.

Altheide, D. L., \& Snow, R. P. (1985). Media logic. Thousand Oaks, CA: Sage Publications.

Balmas, M. (2014). When fake news becomes real: Combined exposure to multiple news sources and political attitudes of inefficacy, alienation, and cynicism. Communication Research, 41(3), 430-454.

Baumeister, R. F., \& Leary, M. R. (1995). The need to belong: Desire for interpersonal attachments as a fundamental human motivation. Psychological Bulletin, 117(3), 497-529.

Beck, U., Giddens, A., \& Lash, S. (1994). Reflexive modernization: Politics, tradition and aesthetics in the modern social order. Stanford, CA: Stanford University Press.

Belk, R. W. (1988). Possessions and the extended self. Journal of Consumer Research, 15(2), 139-168.

Bertel, T. F. (2013). "It's like I trust it so much that I don't really check where it is I'm going before I leave": Informational uses of smartphones among Danish youth. Mobile Media \& Communication, 1(3), 299-313.

Bourdieu, P. (2005). Habitus: A sense of place. In J. Hillier \& E. Rooksby (Eds.), Habitus: A sense of place (pp. 43-52). London: Routledge.

Campbell, S. W., \& Park, Y. J. (2008). Social implications of mobile telephony: The rise of personal communication society. Sociology Compass, 2(2), 371-387.

Castells, M. (2009). Rise of the network society, with a new preface: The information age: Economy, society, and culture volume I. Oxford: Blackwell.

Castells, M., Fernandez-Ardevol, M., Qiu, J. L., \& Sey, A. (2009). Mobile communication and society: A global perspective. Cambridge, MA: MIT Press.

Chayko, M. (2012). Connecting: How we form social bonds and communities in the Internet age. Albany, NY: SUNY Press.

Crawford, K., Lingel, J., \& Karppi, T. (2015). Our metrics, ourselves: A hundred years of self-tracking from the weight scale to the wrist wearable device. European Journal of Cultural Studies, 18(4/5), 479-496.

Cumiskey, K. M., \& Hjorth, L. (2017). Haunting hands: Mobile media practices and loss. Oxford: Oxford University Press.
Dahlgren, P. (1996). Media logic in cyberspace: Repositioning journalism and its publics. Javnost-The Public, 3(3), 59-72.

DeSanctis, G., \& Poole, M. S. (1994). Capturing the complexity in advanced technology use: Adaptive structuration theory. Organization Science, 5(2), 121-147.

Deuze, M. (2011). Media life. Media, Culture \& Society, 33(1), 137-148.

Foucault, M. (1995). Discipline \& punish: The birth of the prison (2nd ed., A. Sheridan, Trans.). New York, NY: Vintage Books.

Gergen, K. J. (2002). The challenge of absent presence. In J. E. Katz \& M. Aakhus (Eds.), Perpetual contact: Mobile communication, private talk, public performance (pp. 227-241). Cambridge: Cambridge University Press.

Giddens, A. (1984). The constitution of society: Outline of the theory of structuration. Berkeley, CA: University of California Press.

Giddens, A. (1990). The consequences of modernity. Stanford, CA: Stanford University Press.

Giddens, A. (1991). Modernity and self-identity: Self and society in the late modern age. Stanford, CA: Stanford University Press.

Giddens, A. (1993). The transformation of intimacy: Love, sexuality and eroticism in modern society. Cambridge: Polity.

Green, N. (2002). On the move: Technology, mobility, and the mediation of social time and space. The Information Society, 18(4), 281-292.

Hand, M. (2016). Persistent traces, potential memories: Smartphones and the negotiation of visual, locative, and textual data in personal life. Convergence, 22(3), 269-286.

Hesselberth, P. (2017). Discourses on disconnectivity and the right to disconnect. New Media \& Society, 1-17. doi:10.1177/1461444817711449

Heyman, R., De Wolf, R., \& Pierson, J. (2014). Evaluating social media privacy settings for personal and advertising purposes. Info, 16(4), 18-32.

Hopper, R. (1992). Telephone conversation. Bloomington, IN: Indiana University Press.

Hussain, M. M., \& Howard, P. N. (2013). What best explains successful protest cascades? ICTs and the fuzzy causes of the Arab Spring. International Studies Review, 15(1), 48-66.

Hutchby, I. (2001). Technologies, texts and affordances. Sociology, 35(2), 441-456.

Katz, J. E., \& Aakhus, M. A. (2002). Conclusion: Making meaning of mobiles-A theory of Apparatgeist. In J. E. Katz \& M. A. Aakhus (Eds.), Perpetual contact: Mobile communication, private talk, public performance (pp. 301-320). Cambridge: Cambridge University Press.

Katz, J. E., \& Sugiyama, S. (2016). Mobile phones as fashion statements: Evidence from student surveys in the US and Japan. New Media \& Society, 8(2), 321-337.

Kubitschko, S., \& Knapp, D. (2012). An invisible life? A response to Mark Deuze's 'media life'. Media, Culture \& Society, 34(3), 359-364. 
Leaver, T. (2017). Intimate surveillance: Normalizing parental monitoring and mediation of infants online. Social Media \& Society, 3(2), 1-10.

Licoppe, C. (2004). 'Connected' presence: The emergence of a new repertoire for managing social relationships in a changing communication technoscape. Environment and Planning D: Society and Space, 22(1), 135-156.

Licoppe, C., \& Heurtin, J. P. (2001). Managing one's availability to telephone communication through mobile phones: A French case study of the development dynamics of mobile phone use. Personal and Ubiquitous Computing, 5(2), 99-108.

Lindgren, S. (2017). Digital media \& society. London: Sage Publications

Ling, R. (2004). The mobile connection: The cell phone's impact on society. San Francisco, CA: Morgan Kaufmann.

Ling, R. (2008a). Mobile telephones and the disturbance of the public sphere. Europe, 115, 1-17.

Ling, R. (2008b). New tech, new ties. Cambridge, MA: MIT Press.

Ling, R. (2012). Taken for grantedness: The embedding of mobile communication into society. Cambridge, MA: MIT Press.

Ling, R. (2017). A brief history of individual addressability: The role of mobile communication in being permanently connected. In P. Vorderer, D. Hefner, L. Reinecke, \& C. Klimmt (Eds.), Permanently online, permanently connected (pp. 10-17). London: Routledge.

Ling, R., \& Haddon, L. (2003). Mobile telephony, mobility, and the coordination of everyday life. In J. E. Katz (Ed.), Machines that become us: The social context of personal communication technology (pp. 245-265). New Brunswick, NJ: Transaction Publishers.

Ling, R., \& Lai, C.-H. (2016). Microcoordination 2.0: Social coordination in the age of smartphones and messaging apps. Journal of Communication, 66(5), 834-856.

Ling, R., \& Yttri, B. (1999). Nobody sits at home and waits for the telephone to ring: Micro and hypercoordination through the use of the mobile telephone (Telenor Forskning og Utvikling, FoU Rapport, 30(99)). Retrieved from http://citeseerx.ist.psu.edu/ viewdoc/download?doi=10.1.1.180.1209\&rep=rep1 \&type=pdf

Malinowski, B. (1972). Phatic communion. In J. Laver \& S. Hutcheson (Eds.), Communication in face-to-face interaction (pp. 146-152). Harmondworth: Penguin Books.

Mann, S., Nolan, J., \& Wellman, B. (2002). Sousveillance: Inventing and using wearable computing devices for data collection in surveillance environments. Surveillance \& Society, 1(3), 331-355.

Marcía-Montes, J. M., Caballero-Muñoz, D. \& PérezÁlvarez, M. (2006). Changes in the self resulting from the use of mobile phones. Media, Culture and Society, 28(1), 67-82.

Marwick, A. E. (2012). The public domain: Social surveil- lance in everyday life. Surveillance \& Society, 9(4), 378.

Mattingly, M. J., \& Sayer, L. C. (2006). Under pressure: Gender differences in the relationship between free time and feeling rushed. Journal of Marriage and Family, 68(1), 205-221.

Morris, M. E., \& Aguilera, A. (2012). Mobile, social, and wearable computing and the evolution of psychological practice. Professional Psychology: Research and Practice, 43(6), 622-626.

Nissenbaum, H. (2009). Privacy in context: Technology, policy, and the integrity of social life. Standford, CA: Stanford University Press.

Orlikowski, W. J. (1992). The duality of technology: Rethinking the concept of technology in organizations. Organization Science, 3(3), 398-427.

Papacharissi, Z. (2011). A networked self. In Z. Papacharissi (Ed.), A networked self: Identity, community, and culture on social network sites (pp. 304-318). New York, NY and London: Taylor \& Francis.

Papacharissi, Z., \& Gibson, P. L. (2011). 15 Minutes of privacy: Privacy, sociality and publicity on social network sites. In S. Reinecke \& S. Trepte (Eds.), Privacy online theoretical approaches and research perspectives on the role of privacy in the social web (pp. 75-89). New York, NY: Springer.

Rainie, L., \& Wellman, B. (2012). Networked: The new social operating system. Cambridge, MA: MIT Press.

Rosa, H. (2013). Social acceleration: A new theory of modernity. New York, NY: Columbia University Press.

Silverstone, R., \& Haddon, L. (1996). Design and the domestication of information and communication technologies: Technical change and everyday life. In R. Mansell \& R. Silverstone (Eds.), Communication by design: The politics of information and communication technologies (pp. 44-74). Oxford: Oxford University Press.

Simmel, G. (1950). The sociology of georg simmel: Translated, edited and with an introduction by Kurt $\mathrm{H}$. Wolff. New York, NY: The Free Press.

Smythe, D. W. (1977). Communications: Blindspot of Western Marxism. Canadian Journal of Political and Social Theory, 1(3), 1-27.

Taylor, A. S., \& Harper, R. (2003). The gift of the gab? A design oriented sociology of young people's use of mobiles. Computer Supported Cooperative Work (CSCW), 12(3), 267-296.

Turkle, S. (2011). Alone together: Why we expect more from technology and less from ourselves. New York, NY: Basic Books.

Van Dijck, J. (2013). The culture of connectivity: A critical history of social media. New York, NY: Oxford University Press.

Van Dijck, J. (2014). Datafication, dataism and dataveillance: Big Data between scientific paradigm and ideology. Surveillance \& Society, 12, 197-208.

Van Dijck, J., \& Poell, T. (2013). Understanding social media logic. Media and Communication, 1(1), 2-14. 
Vanden Abeele, M. M. (2016). Mobile youth culture: A conceptual development. Mobile Media \& Communication, 4(1), 85-101.

Vanden Abeele, M. M. P., Antheunis, M. L., \& Schouten, A. P. (2016). The effect of mobile messaging during a conversation on impression formation and interaction quality. Computers in Human Behavior, 62, 562-569.

Vishwanath, A., \& Chen, H. (2008). Personal communication technologies as an extension of the self: A cross-cultural comparison of people's associations with technology and their symbolic proximity with others. Journal of the Association for Information Science and Technology, 59(11), 1761-1775.

Vorderer, P., Krömer, N., \& Schneider, F. M. (2016).
Permanently online-Permanently connected: Explorations into university students' use of social media and mobile smart devices. Computers in Human Behavior, 63, 694-703.

Wakefield, A., \& Fleming, J. (2009). The Sage dictionary of policing. Los Angeles, CA and London: Sage Publications.

Wellman, B., \& Berkowitz, S. D. (1988). Social structures: A network approach (Vol. 2): Cambridge: CUP Archive.

Wurtzel, A. H., \& Turner, C. (1976). Latent functions of the telephone: What missing the extension means. In I. de Sola Pool (Ed.), The social impact of the telephone (pp. 246-261). Cambridge, MA: MIT Press.

\section{About the Authors}

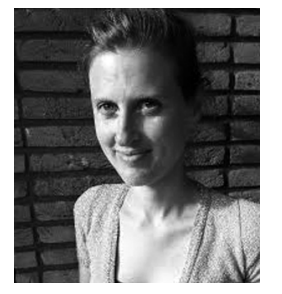

Mariek Vanden Abeele (PhD, University of Leuven) is assistant professor at the department of Communication and Information Sciences, Tilburg University, the Netherlands. Her research focuses on the social implications of mobile media, including the impact of (co-present) mobile media use on impression formation and relationship quality, problematic mobile media use, and children's and adolescents' mobile media use.

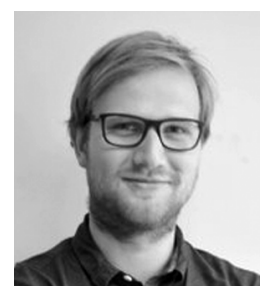

Ralf De Wolf (PhD, Free University of Brussels) is a doctoral assistant at the Department of Communication Studies and connected to the research group for Media, Innovation and Communication Technologies (imec-mict-UGent), Ghent University, Belgium. His current research focuses on the privacy management of children and youngsters, presentation of self and new media.

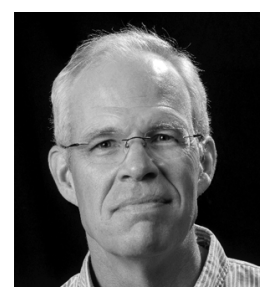

Rich Ling (PhD Sociology, University of Colorado) is the Shaw Foundation Professor of Media Technology, at Nanyang Technological University, Singapore. He also works with Telenor, the Norwegian Telecommunication Operator. For the past two decades, Ling has studied the social consequences of mobile communication. He has written or edited 12 books and over 100 peer reviewed papers and book chapters. He is the author of The Mobile Connection (Morgan Kaufmann, 2004), New Tech, New Ties (MIT, 2008) and Taken for Grantedness (MIT, 2012). He is the editor-in-chief of the Journal of Computer-Mediated Communication, a founding co-editor of Mobile Media and Communication (Sage) and the Oxford University Press Series Studies in Mobile Communication. He was recently named a fellow of the International Communication Association. 